\title{
Facile and Green Synthesis of Starfruit-Like ZIF-L, and Its Optimization Study
}

\author{
Christian J. Wijaya ${ }^{1}$ D, Suryadi Ismadji ${ }^{2,3}$, Hakun W. Aparamarta ${ }^{1}$ and Setiyo Gunawan ${ }^{1, *(D)}$ \\ 1 Department of Chemical Engineering, Faculty of Industrial Technology and Systems Engineering, Institut \\ Teknologi Sepuluh Nopember, Keputih Sukolilo, Surabaya 60111, Indonesia; ch.julius7@gmail.com (C.J.W.); \\ hakun2397@gmail.com (H.W.A.) \\ 2 Department of Chemical Engineering, Widya Mandala Surabaya Catholic University, Kalijudan 37, \\ Surabaya 60114, Indonesia; suryadiismadji@yahoo.com \\ 3 Department of Chemical Engineering, National Taiwan University of Science and Technology, 43 Keelung \\ Road, Sec 4, Taipei 10607, Taiwan \\ * Correspondence: gunawan@chem-eng.its.ac.id; Tel.: +62-31-594-6240; Fax: +62-31-599-9282
}

Citation: Wijaya, C.J.; Ismadji, S.; Aparamarta, H.W.; Gunawan, S.

Facile and Green Synthesis of Starfruit-Like ZIF-L, and Its Optimization Study. Molecules 2021, 26, 4416. https://doi.org/ $10.3390 /$ molecules 26154416

Academic Editors: Giuseppe Cirillo, Manuela Curcio and Orazio Vittorio

Received: 22 June 2021

Accepted: 16 July 2021

Published: 21 July 2021

Publisher's Note: MDPI stays neutral with regard to jurisdictional claims in published maps and institutional affiliations.

Copyright: (c) 2021 by the authors. Licensee MDPI, Basel, Switzerland. This article is an open access article distributed under the terms and conditions of the Creative Commons Attribution (CC BY) license (https:/ / creativecommons.org/licenses/by/ $4.0 /)$.

\begin{abstract}
Due to its excellent characteristics, zeolitic imidazole framework-L (ZIF-L) is widely used in various applications, such as drug delivery, wastewater treatments and energy storage. In the synthesis of ZIF-L, the molar ratio of ligand to metal, the reaction time and the temperature are essential parameters to produce excellent ZIF-L. In this work, ZIF-L was synthesized using a facile and green synthesis method. It was statistically investigated and optimized to obtain the best operating conditions. The optimization was carried out toward the amount of adsorbed crystal violet $(\mathrm{CV})$ dye $(q)$ as the response in the statistics. The optimal ZIF-L was obtained using a molar ratio of ligand to metal of 8.2220 for $97 \mathrm{~min}$ at $29^{\circ} \mathrm{C}$, where the $q$ value of the $\mathrm{CV}$ adsorption onto this optimal ZIF-L reached $823.02 \mathrm{mg} / \mathrm{g}$. The obtained ZIF-L was characterized using SEM, XRD, FTIR and TGA analyses to ensure its excellent characteristics.
\end{abstract}

Keywords: crystal violet adsorption; healthy; optimization; starfruit-like shape; zeolitic imidazolate framework-L

\section{Introduction}

Metal-organic frameworks (MOFs) are advanced porous inorganic-organic materials assembled from metal clusters and organic ligands through coordination bonds [1-3]. They have a crystalline structure, large surface area, high pore volume, tunable pore size, good adsorption capacity, good thermal and chemical stability, and flexibility, and are easy to functionalize and modify [4-8]. Due to their outstanding characteristics, they have been applied in many applications, such as selective adsorption [9-11], water and wastewater treatments [12-14], composite constituents [15,16], catalysts and photocatalysts [17,18], fluorescence sensors [1,19], gas storage and separation [20,21], and drug delivery [22,23]. In the last few decades, many types of MOFs have been studied and developed through various synthesis methods, including diffusion, solvo(hydro)thermal, microwave, electrochemical, mechanochemical and sonochemical methods [24].

Zeolitic imidazolate framework-8 (ZIF-8) is a kind of ZIF that is assembled by coordinating zinc $(\mathrm{Zn})$ as the metal-core and 2-methylimidazole (Hmim) as the organic ligand in the 3D structure. Previous studies have been carried out to synthesise ZIFs, especially ZIF-8, in which various surface areas, pore volumes and pore sizes were obtained $[1,25,26]$. ZIF-8 is called a zeolitic MOF due to its similarity to the tetrahedral framework of zeolites [15]. This allows the ZIF-8 to have a rhombic dodecahedron crystal shape $[1,3,25,27]$. However, it did not rule out the formation of other crystal shapes, such as hexagonal [15,28], truncated cubic [26], spherical [29], rod-like, and cylindrical crystal shapes [20]. This phenomenon may occur due to differences in the method, parameters and modulator addition. Even 
though ZIF-8 has excellent characteristics, the 3D structure of ZIF-8 provides a lower adsorption capacity than its $2 \mathrm{D}$ structure [30]. Therefore, another polymorph of ZIF-8 which has a 2D structure was developed to overcome this issue: it is called ZIF-L, and it has the same building units as common ZIF-8 [31-33]. Both ZIF-8 and ZIF-L have been well synthesized in aqueous systems, which are more environmentally friendly. ZIF-L needs a lower molar ratio of ligand to metal compared to ZIF-8, such that the synthesis of ZIF-L is more economical [34]. In the synthesis of ZIF-L, the molar ratio of ligand to metal plays an important role to produce ZIF-L with excellent characteristics $[33,34]$. In this study, two other parameters were also involved besides the molar ratio of ligand to metal in order to further optimize the synthesis of ZIF-L, namely the reaction time and temperatures. Therefore, it is important to carry out statistical process optimization. However, this statistical study has never been performed before in the synthesis of ZIF-8.

Herein, a facile, green and optimal synthesis of ZIF-L was carried out in the aqueous system. This synthesis process only used water as the solvent, which was easier to remove and safer for further applications. The molar ratio of ligand to metal, reaction time and temperature were varied in order to obtain the optimum operating conditions of ZIF-L synthesis. The effects of the parameters used were studied using the one-factor-at-a-time (OFAT) method, while the optimization study was statistically modelled using response surface methodology (RSM). Furthermore, the amount of crystal violet (CV) dye adsorbed onto the synthesized ZIF-L $(q)$ was used as the response in the statistics.

\section{Results and Discussion}

\subsection{One-Factor-at-a-Time (OFAT) Experiments}

\subsubsection{Effects of the Molar Ratio of Ligand to Metal}

In this study, the synthesis of ZIF-L was focused on a lower molar ratio of ligand to metal in order to obtain a more economical synthesis process compared to the synthesis of ZIF-8. However, the reaction time and temperature were also used as other independent parameters here, in addition to the molar ratio, for the adjustment of the optimal synthesis of ZIF-L. In the OFAT experiments for the molar ratio parameter, the synthesis of ZIF-L was detained for a reaction time of $60 \mathrm{~min}$ at a temperature of $30^{\circ} \mathrm{C}$. As shown in Figure 1, the $q$ value increased along with the molar ratio of ligand to metal, but it reversed down after a certain point of the molar ratio of ligand to metal. ZIF-L synthesized using a molar ratio of 7.5 had the highest $q$ value compared to the lower and higher molar ratio. A previous study also reported that the synthesis of ZIF-8 at a lower molar ratio produced ZIF-L with a 2D structure, with a lower surface area and pore volume [35]. Therefore, the low $q$ values of the ZIF-L synthesized here at a lower molar ratio could be hypothesized to be due to the lower surface area and pore volume. Aside from that, the use of a higher molar ratio tended to present an excess ligand initiating high initial nucleation. High numbers of nuclei were formed in the early phase due to the excess amounts of ligand, producing ZIF-L with a smaller crystal size [36]. Due to the higher $q$ value, the molar ratio of 7.5 was used for the further steps of the OFAT experiments. However, the molar ratio of 7.5 did not exactly give the highest $q$ value, as shown by the curve trend in Figure 1. Furthermore, the optimization was carried out using the molar ratios of 5, 7.5, and 10 in order to obtain the optimum synthesis conditions. 


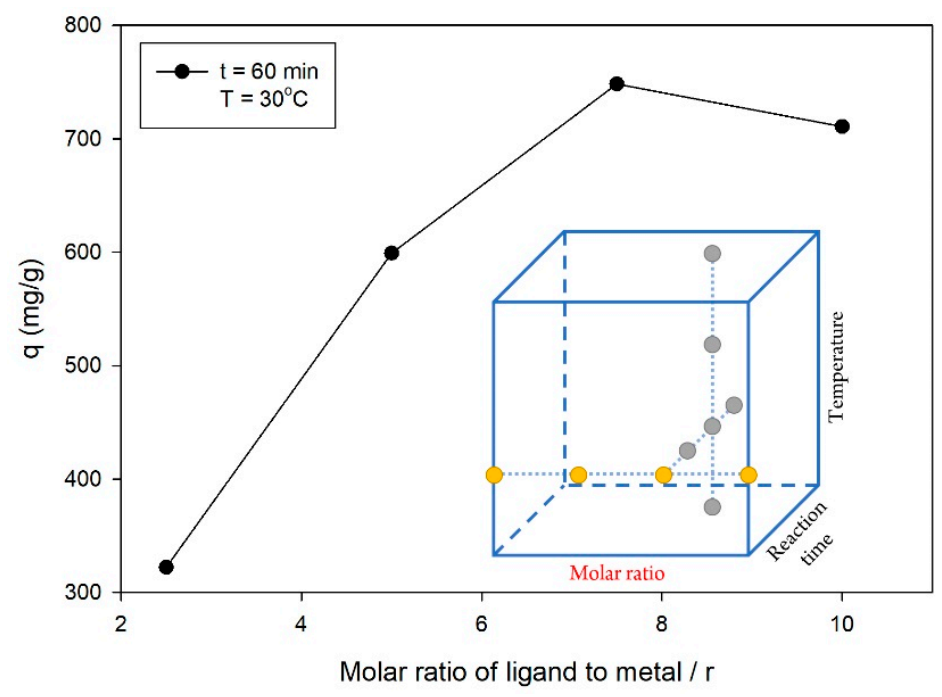

Figure 1. Effect of the molar ratio of ligand to the metal on the $q$ value, with the following experimental conditions: reaction time $=60 \mathrm{~min}$ and temperature $=30^{\circ} \mathrm{C}$.

\subsubsection{Effects of Reaction Time}

In the second series of OFAT experiments for the reaction time parameter, the synthesis of ZIF-L was attained using a molar ratio of 7.5 at a temperature of $30^{\circ} \mathrm{C}$. Figure 2 shows the $q$ values for various reaction times, where the highest $q$ value was obtained for a reaction time of $120 \mathrm{~min}$ among the other levels. The reaction times of 30 and $60 \mathrm{~min}$ were still in the crystal growth phase, such that the formation of ZIF-L had not been completed. Previous studies reported that the ZIF's characteristics in terms of surface area and pore volume increased during the crystal growth phase until a certain time, and then remained constant $[2,20]$. However, Figure 2 shows the decreased $q$ value of ZIF-L synthesized for a reaction time of $180 \mathrm{~min}$. This phenomenon was suspected to occur because of the stuck residual reactants in the ZIF-L pores, which were difficult to wash off, such that the adsorption ability towards $\mathrm{CV}$ decreased significantly. The excess reaction time used in the synthesis allowed the adsorption of residual reactants onto ZIF-L. From these OFAT experiments, the reaction time of $120 \mathrm{~min}$ was used for the next step of the OFAT experiments, while the reaction times of 60,120 and $180 \mathrm{~min}$ were investigated more in the optimization study.

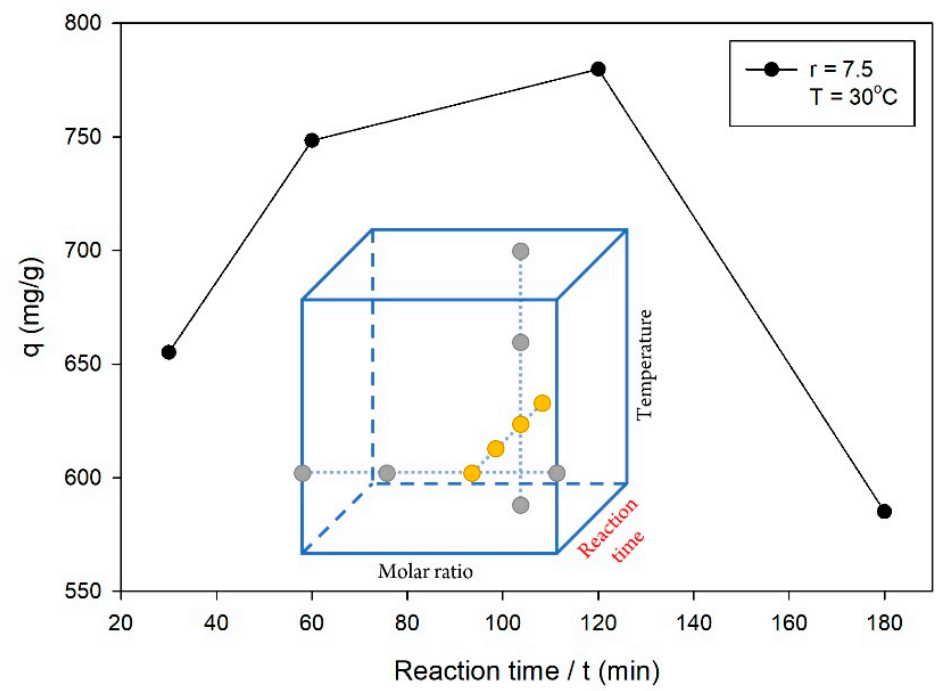

Figure 2. Effect of the reaction time on the $q$ value, with the following experimental conditions: molar ratio of ligand to metal $=7.5$ and temperature $=30{ }^{\circ} \mathrm{C}$. 


\subsubsection{Effects of the Temperature}

In the third series of OFAT experiments, the synthesis of ZIF-L was attained using a molar ratio of 7.5 for a reaction time of $120 \mathrm{~min}$, which was obtained from the two previous series of OFAT experiments. Here, the synthesis of ZIF-L was carried out with variations in temperature, and the results are shown in Figure 3. The highest $q$ value was obtained at a temperature of $30^{\circ} \mathrm{C}$. A previous study reported that ZIFs with a high crystallinity and surface area could be obtained at a specific temperature [20]. The crystallinity and surface area were the main characteristics that affected the $q$ value. In the synthesis of ZIF-L, the use of a low temperature might not be able to remove the amorphous compounds in the ZIF-L, while the high temperature inhibited the formation of ZIF-L, which was shown by the lower yield of ZIF-L. The results of these OFAT experiments were used to determine the parameters in the further optimization study using RSM.

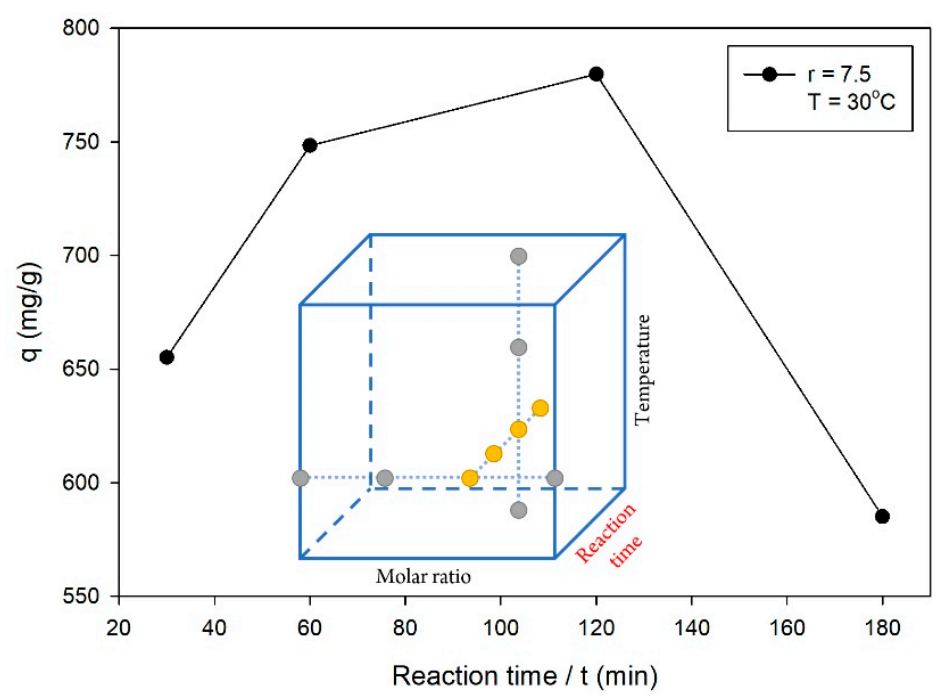

Figure 3. Effect of temperature on the $q$ value, with the following experimental conditions: molar ratio of ligand to metal $=7.5$ and reaction time $=120 \mathrm{~min}$.

\subsection{Response Surface Analysis}

\subsubsection{Central Composite Design (CCD) and Analysis of Variance (ANOVA)}

In this study, CCD was employed due to its ability to provide a good prediction for the entire design space in terms of the effects of linear, quadratic, and two-way interactions. The synthesis of ZIF-L with three independent parameters (the molar ratio of ligand to metal, reaction time and temperature) was designed using five levels for each parameter, as presented in Table 1. Here, the $q$ value was still used as the response in this study. The CCD analysis presented the polynomial equation in order to express the correlation between the independent parameters and the response. The polynomial equation is presented below:

$q=798.02+52.31(r)-86.45(t)-6.82(T)-95.79\left(r^{2}\right)-112.89\left(t^{2}\right)-113.69\left(T^{2}\right)-9.05(r \times t)+14.80(t \times T)$

where $q$ is the amount of adsorbed CV onto ZIF-L, and $r, t$ and $T$ are the coded independent parameters. This equation was also used to calculate the predicted $q$ values for each combined parameter, as presented in Table 1. A CCD analysis was successfully carried out as a statistical model to predict the correlations between the independent parameters and the response. It was evidenced by the high values of $R^{2}, R^{2}($ adj $)$ and $R^{2}$ (pred) of $99.51 \%$, $99.40 \%$ and $99.20 \%$, respectively. 
Table 1. Design of the experiment on the ZIF-L synthesis, along with the experimental and predicted responses.

\begin{tabular}{|c|c|c|c|c|c|c|c|c|c|c|}
\hline \multirow{2}{*}{ Run Order } & \multirow{2}{*}{ Blocks } & \multirow{2}{*}{ Points } & \multicolumn{3}{|c|}{ Coded Parameters } & \multicolumn{3}{|c|}{ Uncoded Parameter } & \multicolumn{2}{|c|}{$q$ as the Response (mg/g) } \\
\hline & & & $r$ & $t$ & $T$ & $r$ & $t$ (min) & $T\left({ }^{\circ} \mathrm{C}\right)$ & Experimental & Predicted \\
\hline $\begin{array}{l}1 \\
2 \\
3 \\
4 \\
5 \\
6 \\
7 \\
8\end{array}$ & \multirow{3}{*}{1} & Cube & $\begin{array}{l}-1 \\
+1 \\
-1 \\
+1 \\
-1 \\
+1 \\
-1 \\
+1\end{array}$ & $\begin{array}{l}-1 \\
-1 \\
+1 \\
+1 \\
-1 \\
-1 \\
+1 \\
+1\end{array}$ & $\begin{array}{l}-1 \\
-1 \\
-1 \\
-1 \\
+1 \\
+1 \\
+1 \\
+1\end{array}$ & $\begin{array}{c}5 \\
10 \\
5 \\
10 \\
5 \\
10 \\
5 \\
10\end{array}$ & $\begin{array}{c}60 \\
60 \\
180 \\
180 \\
60 \\
60 \\
180 \\
180\end{array}$ & $\begin{array}{l}10 \\
10 \\
10 \\
10 \\
50 \\
50 \\
50 \\
50\end{array}$ & $\begin{array}{l}522.32 \\
664.72 \\
336.47 \\
408.43 \\
498.08 \\
585.69 \\
350.26 \\
449.72\end{array}$ & $\begin{array}{l}522.36 \\
645.08 \\
337.96 \\
424.48 \\
479.12 \\
601.84 \\
353.92 \\
440.44\end{array}$ \\
\hline $\begin{array}{c}9 \\
10 \\
11 \\
12 \\
13 \\
14\end{array}$ & & Axial & $\begin{array}{c}-1.68 \\
+1.68 \\
0 \\
0 \\
0 \\
0\end{array}$ & $\begin{array}{c}0 \\
0 \\
-1.68 \\
+1.68 \\
0 \\
0\end{array}$ & $\begin{array}{c}0 \\
0 \\
0 \\
0 \\
-1.68 \\
+1.68\end{array}$ & $\begin{array}{c}3.30 \\
11.70 \\
7.5 \\
7.5 \\
7.5 \\
7.5\end{array}$ & $\begin{array}{c}120 \\
120 \\
19 \\
221 \\
120 \\
120\end{array}$ & $\begin{array}{c}30 \\
30 \\
30 \\
30 \\
-3.6 \\
63.6\end{array}$ & $\begin{array}{l}437.14 \\
621.00 \\
599.45 \\
360.14 \\
479.18 \\
477.81\end{array}$ & $\begin{array}{l}439.11 \\
615.06 \\
624.11 \\
333.33 \\
487.93 \\
464.99\end{array}$ \\
\hline $\begin{array}{l}15 \\
16 \\
17 \\
18 \\
19 \\
20\end{array}$ & & Center & $\begin{array}{l}0 \\
0 \\
0 \\
0 \\
0 \\
0\end{array}$ & $\begin{array}{l}0 \\
0 \\
0 \\
0 \\
0 \\
0\end{array}$ & $\begin{array}{l}0 \\
0 \\
0 \\
0 \\
0 \\
0\end{array}$ & $\begin{array}{l}7.5 \\
7.5 \\
7.5 \\
7.5 \\
7.5 \\
7.5\end{array}$ & $\begin{array}{l}120 \\
120 \\
120 \\
120 \\
120 \\
120\end{array}$ & $\begin{array}{l}30 \\
30 \\
30 \\
30 \\
30 \\
30\end{array}$ & $\begin{array}{l}787.09 \\
811.31 \\
808.36 \\
802.44 \\
798.52 \\
791.53\end{array}$ & $\begin{array}{l}798.02 \\
798.02 \\
798.02 \\
798.02 \\
798.02 \\
798.02\end{array}$ \\
\hline $\begin{array}{l}21 \\
22 \\
23 \\
24 \\
25 \\
26 \\
27 \\
28\end{array}$ & & Cube & $\begin{array}{l}-1 \\
+1 \\
-1 \\
+1 \\
-1 \\
+1 \\
-1 \\
+1\end{array}$ & $\begin{array}{l}-1 \\
-1 \\
+1 \\
+1 \\
-1 \\
-1 \\
+1 \\
+1\end{array}$ & $\begin{array}{l}-1 \\
-1 \\
-1 \\
-1 \\
+1 \\
+1 \\
+1 \\
+1\end{array}$ & $\begin{array}{c}5 \\
10 \\
5 \\
10 \\
5 \\
10 \\
5 \\
10\end{array}$ & $\begin{array}{c}60 \\
60 \\
180 \\
180 \\
60 \\
60 \\
180 \\
180\end{array}$ & $\begin{array}{l}10 \\
10 \\
10 \\
10 \\
50 \\
50 \\
50 \\
50\end{array}$ & $\begin{array}{l}547.40 \\
647.42 \\
350.84 \\
422.30 \\
489.60 \\
607.42 \\
356.08 \\
452.07\end{array}$ & $\begin{array}{l}522.36 \\
645.08 \\
337.96 \\
424.48 \\
479,12 \\
601.84 \\
353.92 \\
440.44\end{array}$ \\
\hline $\begin{array}{l}29 \\
30 \\
31 \\
32 \\
33 \\
34\end{array}$ & 2 & Axial & $\begin{array}{c}-1.68 \\
+1.68 \\
0 \\
0 \\
0 \\
0\end{array}$ & $\begin{array}{c}0 \\
0 \\
-1.68 \\
+1.68 \\
0 \\
0\end{array}$ & $\begin{array}{c}0 \\
0 \\
0 \\
0 \\
-1.68 \\
+1.68\end{array}$ & $\begin{array}{c}3.30 \\
11.70 \\
7.5 \\
7.5 \\
7.5 \\
7.5\end{array}$ & $\begin{array}{c}120 \\
120 \\
19 \\
221 \\
120 \\
120\end{array}$ & $\begin{array}{c}30 \\
30 \\
30 \\
30 \\
-3.6 \\
63.6\end{array}$ & $\begin{array}{l}438.61 \\
632.02 \\
627.63 \\
327.21 \\
490.08 \\
458.00\end{array}$ & $\begin{array}{l}439.11 \\
615.06 \\
624.11 \\
333.33 \\
487.93 \\
464.99\end{array}$ \\
\hline $\begin{array}{l}35 \\
36 \\
37 \\
38 \\
39 \\
40\end{array}$ & & Center & $\begin{array}{l}0 \\
0 \\
0 \\
0 \\
0 \\
0\end{array}$ & $\begin{array}{l}0 \\
0 \\
0 \\
0 \\
0 \\
0\end{array}$ & $\begin{array}{l}0 \\
0 \\
0 \\
0 \\
0 \\
0\end{array}$ & $\begin{array}{l}7.5 \\
7.5 \\
7.5 \\
7.5 \\
7.5 \\
7.5\end{array}$ & $\begin{array}{l}120 \\
120 \\
120 \\
120 \\
120 \\
120\end{array}$ & $\begin{array}{l}30 \\
30 \\
30 \\
30 \\
30 \\
30\end{array}$ & $\begin{array}{l}795.24 \\
798.38 \\
805.92 \\
795.41 \\
816.45 \\
793.29\end{array}$ & $\begin{array}{l}798.02 \\
798.02 \\
798.02 \\
798.02 \\
798.02 \\
798.02\end{array}$ \\
\hline $\begin{array}{l}41 \\
42 \\
43 \\
44 \\
45 \\
46 \\
47 \\
48\end{array}$ & & Cube & $\begin{array}{l}-1 \\
+1 \\
-1 \\
+1 \\
-1 \\
+1 \\
-1 \\
+1\end{array}$ & $\begin{array}{l}-1 \\
-1 \\
+1 \\
+1 \\
-1 \\
-1 \\
+1 \\
+1\end{array}$ & $\begin{array}{l}-1 \\
-1 \\
-1 \\
-1 \\
+1 \\
+1 \\
+1 \\
+1\end{array}$ & $\begin{array}{c}5 \\
10 \\
5 \\
10 \\
5 \\
10 \\
5 \\
10\end{array}$ & $\begin{array}{c}60 \\
60 \\
180 \\
180 \\
60 \\
60 \\
180 \\
180\end{array}$ & $\begin{array}{l}10 \\
10 \\
10 \\
10 \\
50 \\
50 \\
50 \\
50\end{array}$ & $\begin{array}{l}518.82 \\
616.05 \\
343.07 \\
423.69 \\
454.36 \\
605.29 \\
348.15 \\
407.54\end{array}$ & $\begin{array}{l}522.36 \\
645.08 \\
337.96 \\
424.48 \\
479,12 \\
601.84 \\
353.92 \\
440.44\end{array}$ \\
\hline $\begin{array}{l}49 \\
50 \\
51 \\
52 \\
53 \\
54\end{array}$ & 3 & Axial & $\begin{array}{c}-1.68 \\
+1.68 \\
0 \\
0 \\
0 \\
0\end{array}$ & $\begin{array}{c}0 \\
0 \\
-1.68 \\
+1.68 \\
0 \\
0\end{array}$ & $\begin{array}{c}0 \\
0 \\
0 \\
0 \\
-1.68 \\
+1.68\end{array}$ & $\begin{array}{c}3.30 \\
11.70 \\
7.5 \\
7.5 \\
7.5 \\
7.5\end{array}$ & $\begin{array}{c}120 \\
120 \\
19 \\
221 \\
120 \\
120\end{array}$ & $\begin{array}{c}30 \\
30 \\
30 \\
30 \\
-3.6 \\
63.6\end{array}$ & $\begin{array}{l}419.41 \\
617.88 \\
637.00 \\
324.36 \\
486.33 \\
470.88\end{array}$ & $\begin{array}{l}439.11 \\
615.06 \\
624.11 \\
333.33 \\
487.93 \\
464.99\end{array}$ \\
\hline $\begin{array}{l}55 \\
56 \\
57 \\
58 \\
59 \\
60\end{array}$ & & Center & $\begin{array}{l}0 \\
0 \\
0 \\
0 \\
0 \\
0\end{array}$ & $\begin{array}{l}0 \\
0 \\
0 \\
0 \\
0 \\
0\end{array}$ & $\begin{array}{l}0 \\
0 \\
0 \\
0 \\
0 \\
0\end{array}$ & $\begin{array}{l}7.5 \\
7.5 \\
7.5 \\
7.5 \\
7.5 \\
7.5\end{array}$ & $\begin{array}{l}120 \\
120 \\
120 \\
120 \\
120 \\
120\end{array}$ & $\begin{array}{l}30 \\
30 \\
30 \\
30 \\
30 \\
30\end{array}$ & $\begin{array}{l}780.22 \\
780.15 \\
788.73 \\
794.52 \\
810.04 \\
806.20\end{array}$ & $\begin{array}{l}798.02 \\
798.02 \\
798.02 \\
798.02 \\
798.02 \\
798.02\end{array}$ \\
\hline
\end{tabular}


Furthermore, an ANOVA study was conducted to identify the significance of three independent parameters for the response. The $F$-values and $p$-values are presented to indicate the significances in Table 2. Here, the $p$-value of the model term was significant ( $p$-value $<0.05)$, where this means that the model used fitted the experimental data well. The significances of three independent parameters (linear) and their quadratic and two-way interactions are indicated by an $F$-value higher than its minimum limit and a $p$-value lower than $5 \%(0.05)$. As shown in Table 2, only the two-way interaction between the molar ratio and temperature $(r \times T)$ was not significant, based on a low $F$-value and a $p$-value higher than 0.05. This interpretation is also expressed in the Pareto chart (Figure 4), in which only the two-way interaction between the molar ratio and the temperature $(A C)$ does not cross the reference line of statistical significance. Moreover, this model's lack-of-fit was not significant due to its $p$-value higher than 0.05 , as shown in Table 2, meaning that this model could precisely interpret the fit of the model on the experimental data.

Table 2. Analysis of variance results.

\begin{tabular}{|c|c|c|c|c|c|}
\hline Source & Sum of Squares & Degree of Freedom & Mean Square & $F$-Value & $p$-Value \\
\hline Model & $1,688,160$ & 11 & 153,469 & 894.54 & 0.000 \\
\hline Blocks & 1271 & 2 & 635 & 3.70 & 0.032 \\
\hline$r$ & 112,111 & 1 & 112,111 & 653.47 & 0.000 \\
\hline$t$ & 306,223 & 1 & 306,223 & 1784.91 & 0.000 \\
\hline$T$ & 1907 & 1 & 1907 & 11.12 & 0.002 \\
\hline$r^{2}$ & 396,686 & 1 & 396,686 & 2312.20 & 0.000 \\
\hline$t^{2}$ & 551,006 & 1 & 551,006 & 3211.70 & 0.000 \\
\hline$T^{2}$ & 558,801 & 1 & 558,801 & 3257.14 & 0.000 \\
\hline$r \times t$ & 1965 & 1 & 1965 & 11.45 & 0.001 \\
\hline$r \times T$ & 94 & 1 & 94 & 0.55 & $0.463 *$ \\
\hline$t \times T$ & 5260 & 1 & 5260 & 30.66 & 0.000 \\
\hline Residual & 8235 & 48 & 172 & & \\
\hline Lack-of-fit & 6585 & 33 & 200 & 1.81 & 0.110 * \\
\hline Pure error & 1650 & 15 & 110 & & \\
\hline Total & $1,696,395$ & 59 & & & \\
\hline
\end{tabular}

* not significant.

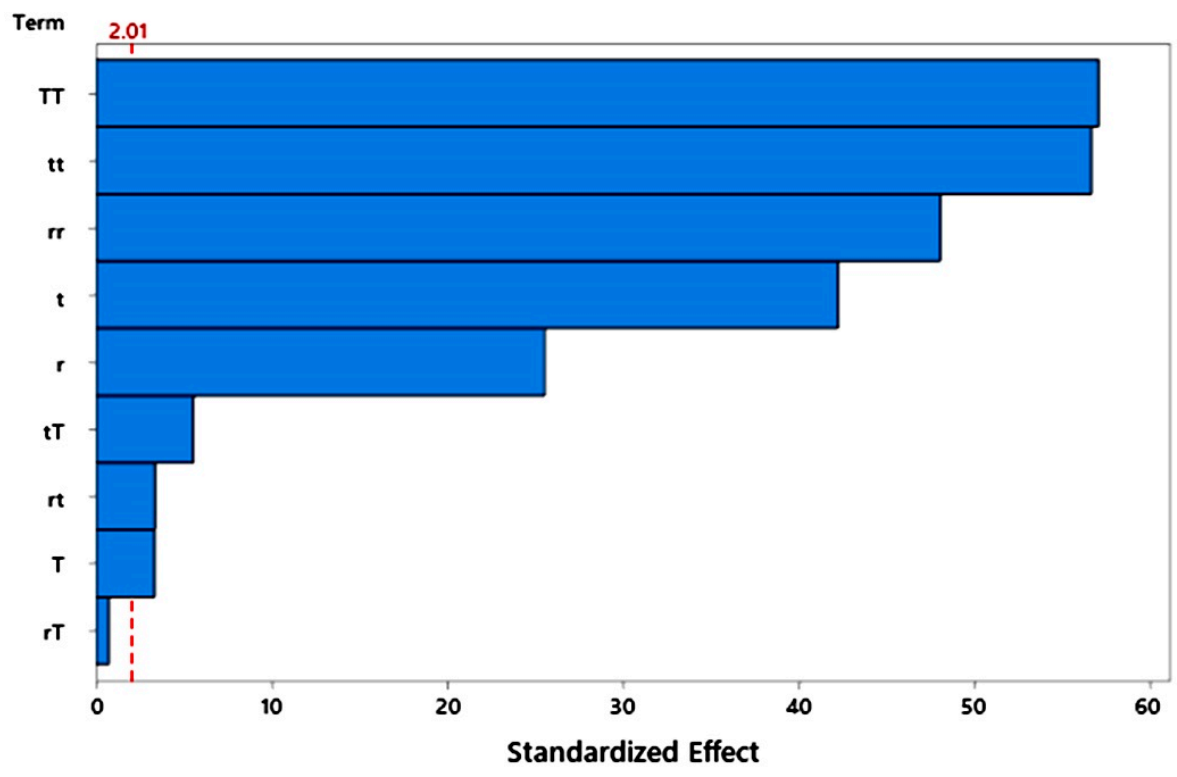

Figure 4. Pareto chart of the standardized effects of the independent parameters on the synthesis of ZIF-L, as measured by the $q$ response. 


\subsubsection{Response Surface Plots}

Figure 5 presents the 3D surface plots that describe the interaction effects between two out of three independent parameters whilst holding another parameter at its optimum level. As shown in Figure 5, the 3D surface plots already had their response peaks ( $q$ value). This means that the statistical design could represent the optimization study, as there was an escalation and depreciation of the response data.
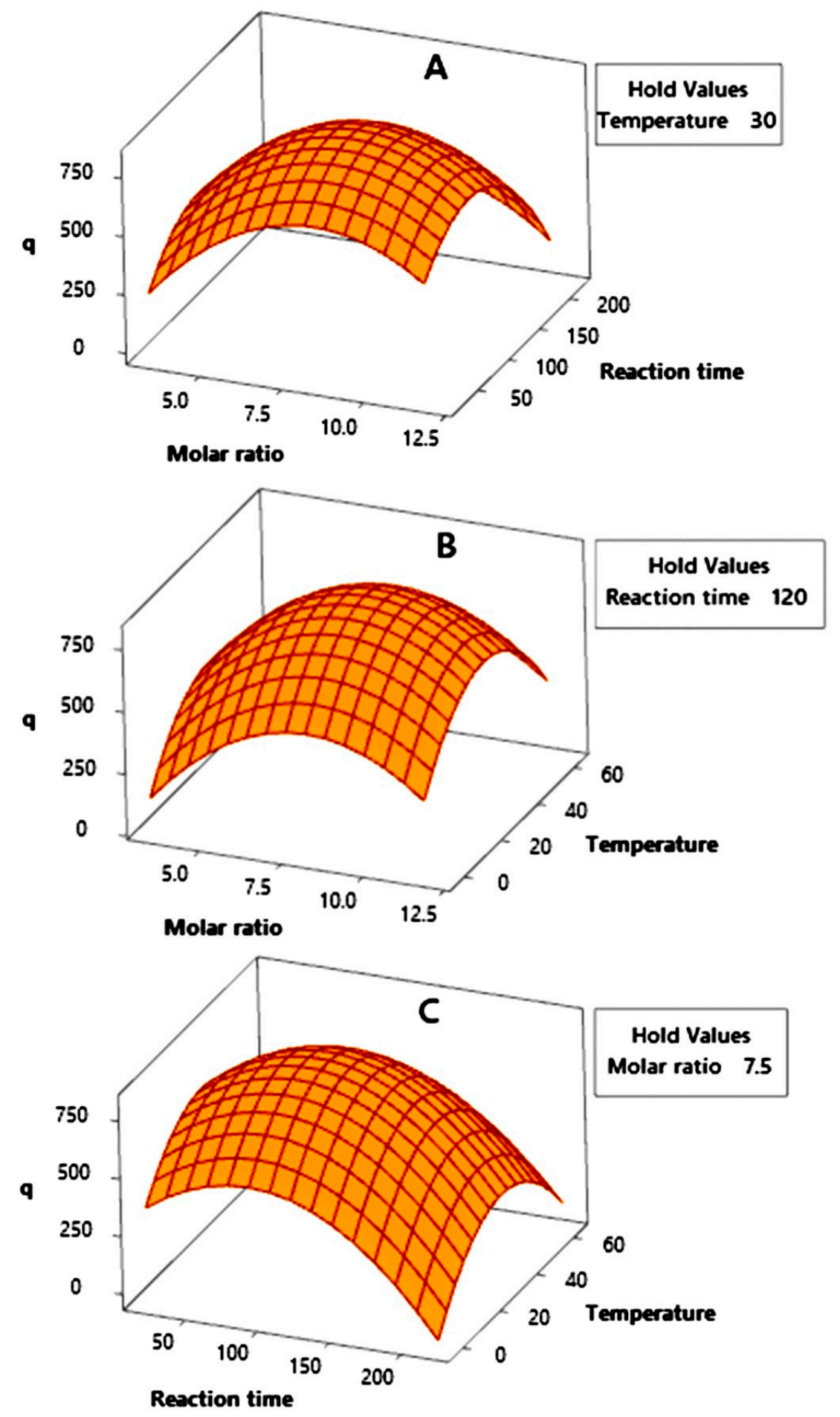

Figure 5. 3D surface plots of the interaction effects between (A) the molar ratio and the reaction time, (B) the molar ratio and the temperature, and $(\mathbf{C})$ the reaction time and the temperature on the synthesis of ZIF-L, as measured by the $q$ response. 
Figure 5A describes the interaction between the molar ratio and the reaction time, with the temperature as the hold parameter. The highest point of the $q$ value was obtained around a molar ratio of 8 and a reaction time of $100 \mathrm{~min}$. This interpretation is continued in Figure 5B, which describes the interaction between the molar ratio and the temperature, with the reaction time as the hold parameter. This surface plot peak was obtained around a temperature of $30{ }^{\circ} \mathrm{C}$ and the same molar ratio as in Figure 5A. The interpretation of these 3D surface plots is confirmed by Figure 5C, in which the peak was obtained in the interaction between the same values of the reaction time and temperature. Furthermore, an optimization study was carried out to determine the real values of these three independent parameters in order to obtain the optimum $q$ value.

\subsubsection{Optimization and Validation}

An optimization study was conducted to obtain the optimum $q$ value based on the variations of three independent parameters. Here, the response's target (or upper value) was set at $850.0 \mathrm{mg} / \mathrm{g}$, or $85 \%$ of the initial CV concentration. The target set exceeded the removal efficiency of several dyes onto ZIFs in the previous study. The removal efficiency of rhodamine $B(\mathrm{RB})$, methyl orange (MO) and methylene blue $(\mathrm{MB})$ reached $50.0 \%, 50.5 \%$ and $46.6 \%$, respectively [37]. As shown in Figure 6, the optimum ZIF-L could be obtained by a synthesis process using a molar ratio of 8.2220 for a reaction time of $97 \mathrm{~min}$ at a temperature of $29^{\circ} \mathrm{C}$, where the highest $q$ value of $\mathrm{CV}$ adsorption onto this ZIF-L reached $823.02 \mathrm{mg} / \mathrm{g}$. This indicates that the removal efficiency of CV onto ZIF-L reached $82.3 \%$, which was higher than the removal efficiency of RB, MO and MB using ZIFs from the previous study. As shown in Figure 6, the composite desirability of this optimization study reached 0.9487 , close to 1 , meaning that the result gave a satisfying optimization for this synthesis of ZIF-L. However, this optimization result still needed validation, and so the synthesis of ZIF-L was performed again using the optimal conditions. The validation was used to ensure the accuracy and consistency of the optimization result.

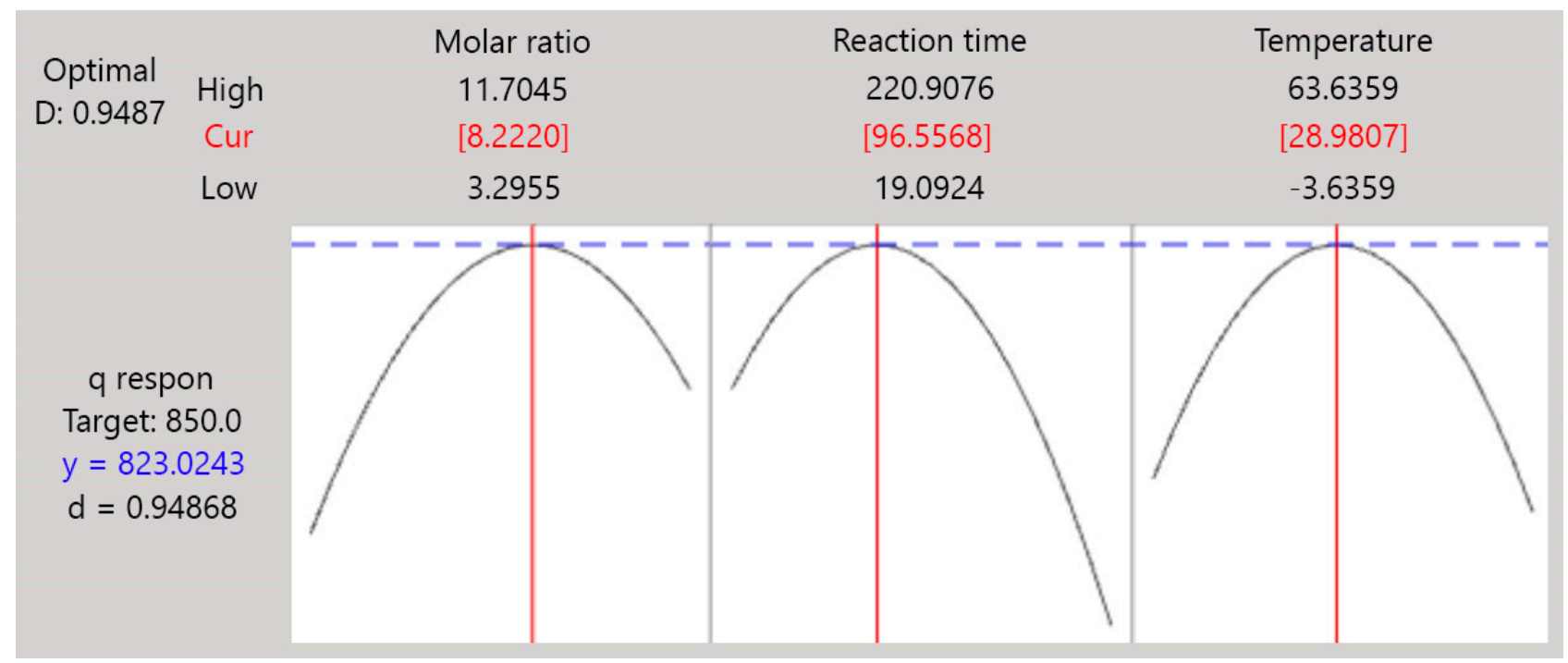

Figure 6. Optimization plots of the independent parameters for the synthesis of ZIF-L.

Table 3 represents the optimization study validation results, where the synthesis of ZIF-L was performed three times using a molar of 8.2220 for $97 \mathrm{~min}$ at $29^{\circ} \mathrm{C}$. The mean $q$ value was $810.32 \pm 9.25 \mathrm{mg} / \mathrm{g}$ from three runs of the synthesis process. The standard deviation of $9.25 \mathrm{mg} / \mathrm{g}(1.14 \%)$ was low enough to indicate this synthesis process's consistency and repeatability. Furthermore, the optimization study error was $1.54 \pm 1.12 \%$, comparing the $q$ values from the optimization and validation studies. The optimization study had a high accuracy, as proven by this low error value. 
Table 3. Validation results of the optimization study on the synthesis of ZIF-L.

\begin{tabular}{|c|c|c|c|c|}
\hline Runs & $\underset{(r)}{\text { Molar Ratio of Ligand to Metal }}$ & $\begin{array}{l}\text { Reaction Time } \\
\quad(t \text { in min })\end{array}$ & $\begin{array}{l}\text { Temperature } \\
\left(T \text { in }{ }^{\circ} \mathrm{C}\right)\end{array}$ & $q \underset{(\mathrm{mg} / \mathrm{g})}{q \text { Response }}$ \\
\hline $\begin{array}{l}1 \\
2 \\
3\end{array}$ & 8.2220 & 97 & 29 & $\begin{array}{l}808.21 \\
802.30 \\
820.43\end{array}$ \\
\hline \multicolumn{4}{|c|}{$\begin{array}{c}\text { Mean value } \\
\text { Optimized value } \\
\text { Error }(\%)\end{array}$} & $\begin{array}{c}810.32 \pm 9.25 \\
823.02 \\
1.54 \pm 1.12\end{array}$ \\
\hline
\end{tabular}

\subsection{Characterizations of ZIF- $L$}

\subsubsection{Scanning Electron Microscopy (SEM) Analysis}

The characterizations were conducted for the ZIF-L obtained from the optimum synthesis process. Figure 7A,B shows the SEM images of the ZIF-L synthesized with and without the sonication step of the metal and ligand solutions. The synthesis with the sonication step produced a better shape of ZIF-L, the starfruit-like shape shown in Figure 7B. Figure 7A shows the aggregated ZIF-L, which would have a lower capability in further applications. In this study, the sonication step helped to produce the more homogeneous starfruit-like shape of ZIF-L. As seen in Figure 7B, the starfruit-like shape of ZIF-L was constructed by the 2D structures of ZIF-L which crossed each other. A previous study showed that MOFs with the same primary building units as ZIF-8, called ZIF-L, could be obtained at any range of molar ratio, including at a low molar ratio of ligand to metal $[2,31,38]$. However, the topotactic transition from the primary to the secondary building units is different, such that ZIF-L has a different crystal structure from ZIF-8 [2]. This synthesis of ZIF-L economically saved the amount of ligand used compared to the synthesis of ZIF-8, which commonly uses a molar ratio of ligand to metal of 70. However, ZIF-L retains excellent characteristics, even better than those of ZIF-8.
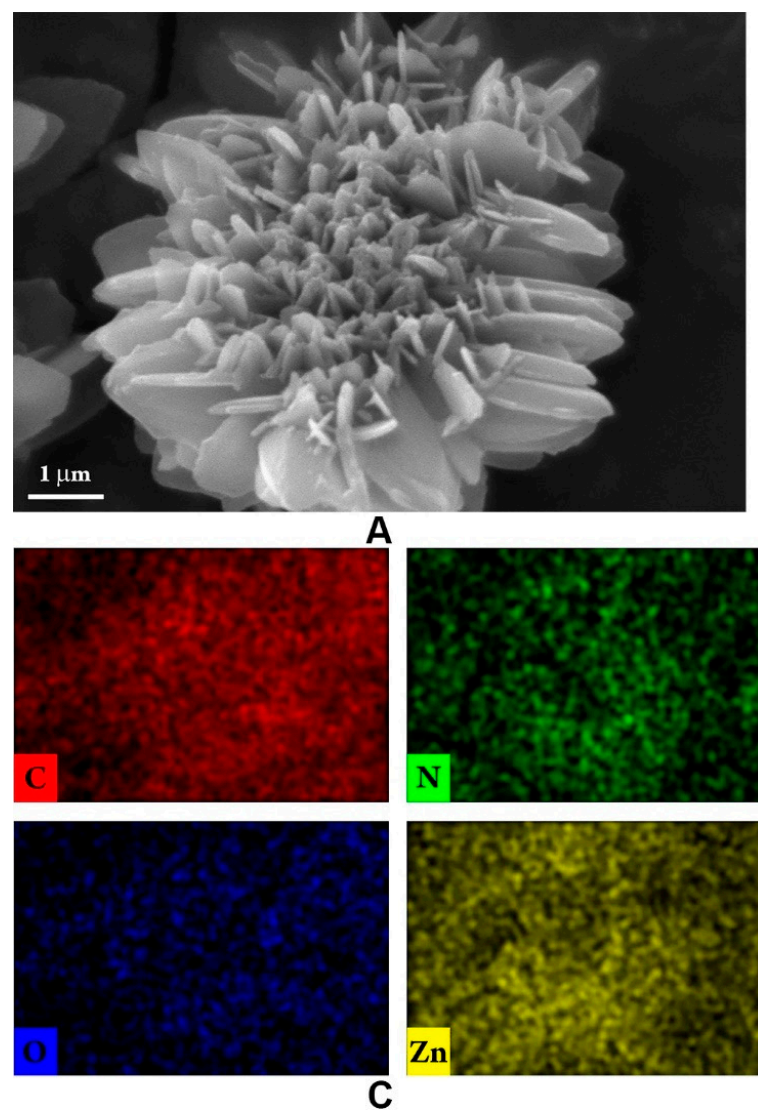

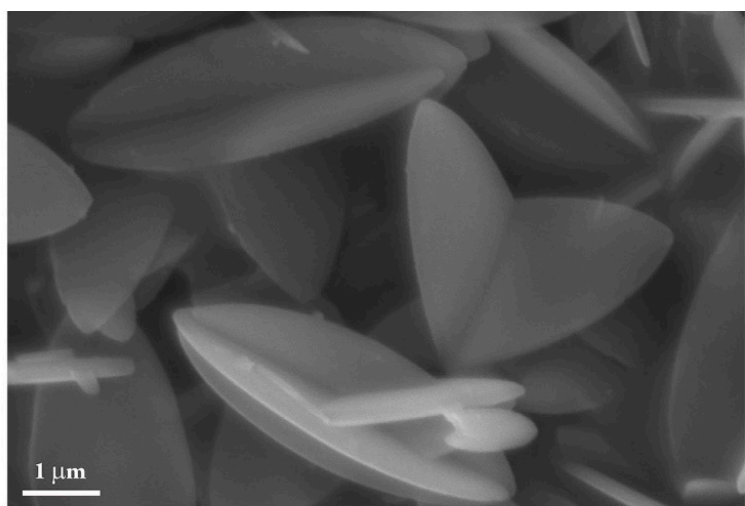

B

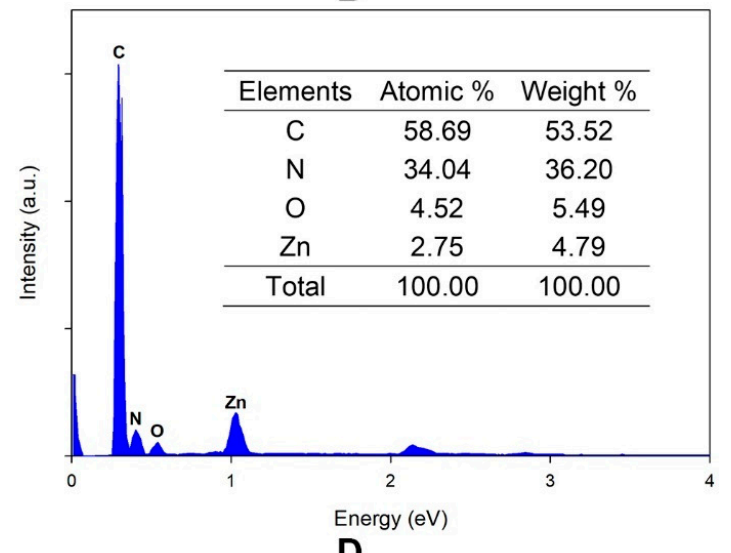

D

Figure 7. SEM photography of the ZIF-L synthesized (A) without the sonication step and (B) with the sonication step, along with (C) EDX mapping and (D) EDX analysis. 
An EDX analysis was carried out to ensure the distribution of the main elements of ZIF-L. In the EDX mapping (Figure 7C), the red, green, blue and yellow colours indicated the distribution of the $\mathrm{C}, \mathrm{N}, \mathrm{O}$ and $\mathrm{Zn}$ elements, respectively. It showed a good distribution of the elements in the ZIF-L. Moreover, the quantitative amounts of each element are figured out in Figure 7D, where the mass percentages of $C, N, O$ and $Z n$ elements in the ZIF-L are shown in the inset table.

\subsubsection{X-ray Diffraction (XRD) Analysis}

The crystallinity of the ZIF-L was characterized using XRD analysis. As shown in Figure 8, the diffraction peaks of ZIF-L at the (110), (200), (211), (220), (310) and (222) planes were observed at $2 \theta$ values of $7.58^{\circ}, 10.80^{\circ}, 12.54^{\circ}, 14.95^{\circ}, 16.49^{\circ}$ and $17.86^{\circ}$, respectively. This result had an excellent agreement with several reports from previous studies $[14,20,28,34,39]$. This proves that ZIF-L was successfully synthesized to have a high crystallinity.

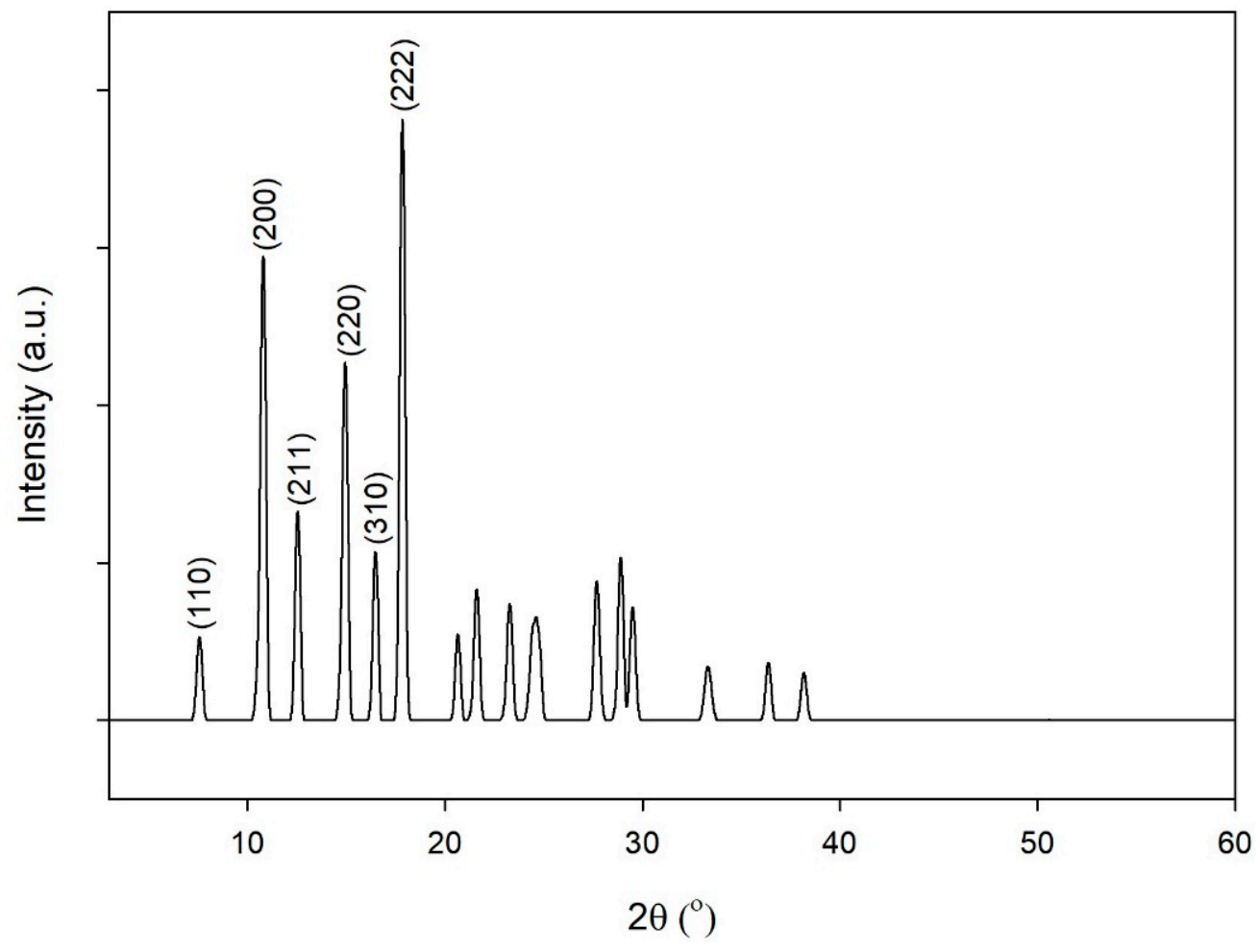

Figure 8. XRD spectra of ZIF-L.

\subsubsection{Fourier-Transform Infrared Spectroscopy (FTIR) Analysis}

The functional groups of the ZIF-L were characterized using FTIR analysis. Figure 9 shows the FTIR spectra of the zinc precursor, ligand and ZIF-L. The spectrum of ZIF-L was similar to the spectra of the zinc precursor and ligand, meaning that the functional groups of ZIF-L were constructed from the functional groups of the zinc precursor and ligand. In the fingerprint region, several transmittance peaks were observed to identify the functional groups of the ZIF-L. The peaks observed at $420.5,756.0$ and $900-1350 \mathrm{~cm}^{-1}$ are associated with the Zn-N stretching of ZIF-L, the out-of-plane bending of the Hmim ring, and the in-plane bending of the Hmim ring, respectively $[2,29,34,38,40]$. 


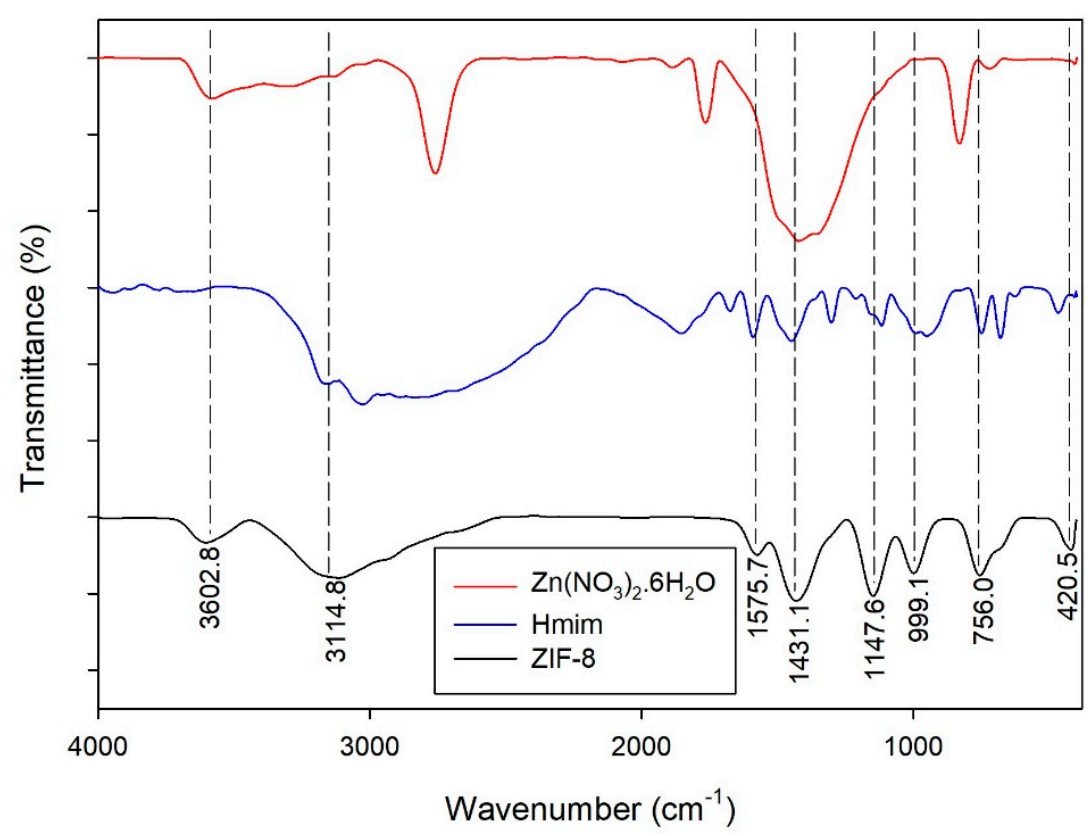

Figure 9. FTIR spectra of $\mathrm{Zn}\left(\mathrm{NO}_{3}\right)_{2} \cdot 6 \mathrm{H}_{2} \mathrm{O}, \mathrm{Hmim}$ and ZIF-L.

In more detail, the in-plane bending of the Hmim ring consists of $\mathrm{C}-\mathrm{N}$ vibration, $\mathrm{C}=\mathrm{N}$ vibration, ring stretching, and $\mathrm{N}-\mathrm{H}$ stretching assigned at 999.1, 1147.6, 1431.1 and $1575.1 \mathrm{~cm}^{-1}$, respectively $[2,29,34,38,40]$. Aside from the fingerprint region, two peaks were observed at 3114.8 and $3602.8 \mathrm{~cm}^{-1}$, which correspond to the aromatic $\mathrm{C}-\mathrm{H}$ stretching of $\mathrm{Hmim}$ and the O-H stretching vibration of adsorbed water [2,29,40]. Here, the water as the solvent in the synthesis process is seen by the presence of an $\mathrm{O}-\mathrm{H}$ stretching vibration peak in this spectrum of ZIF-L. There are no unidentified peaks in the spectrum of ZIF-L, and so no impurities affect the ZIF-L structure. A previous study reported the synthesis of ZIFs, especially ZIF-8, with the addition of a modulator, such as acetic acid [29]. Although the modulator could manage the formation of specific spherical ZIF-8, it gave additional functional groups in the ZIF-8 structure.

\subsubsection{Thermalgravimetric Analysis (TGA)}

A TGA analysis was carried out for ZIF-L under a nitrogen flow, and the results are presented as the TGA and DTG curves in Figure 10. These results were compared with several previous studies, and they show a similar pattern of weight loss [34,38]. As shown in the TGA curve, the first weight loss gradually occurred at temperatures below $275^{\circ} \mathrm{C}$. This weight loss might be caused by the removal of moisture content and residual ligand from the ZIF-L surface. The removal of residual ligand was also indicated by the highest rate of weight loss at $272{ }^{\circ} \mathrm{C}$, as shown by the DTG curve. Next, the good thermal stability of ZIF-L was observed at temperatures between 275 and $475{ }^{\circ} \mathrm{C}$, where a long plateau was seen in the TGA curve. At temperatures above $475^{\circ} \mathrm{C}$, the ZIF-L structure began to collapse, as indicated by significant weight loss. However, this weight loss rate was minimal, as shown in the DTG curve, such that the collapse of the ZIF-L structure occurred gradually and took a long time in reasonably high temperatures. 


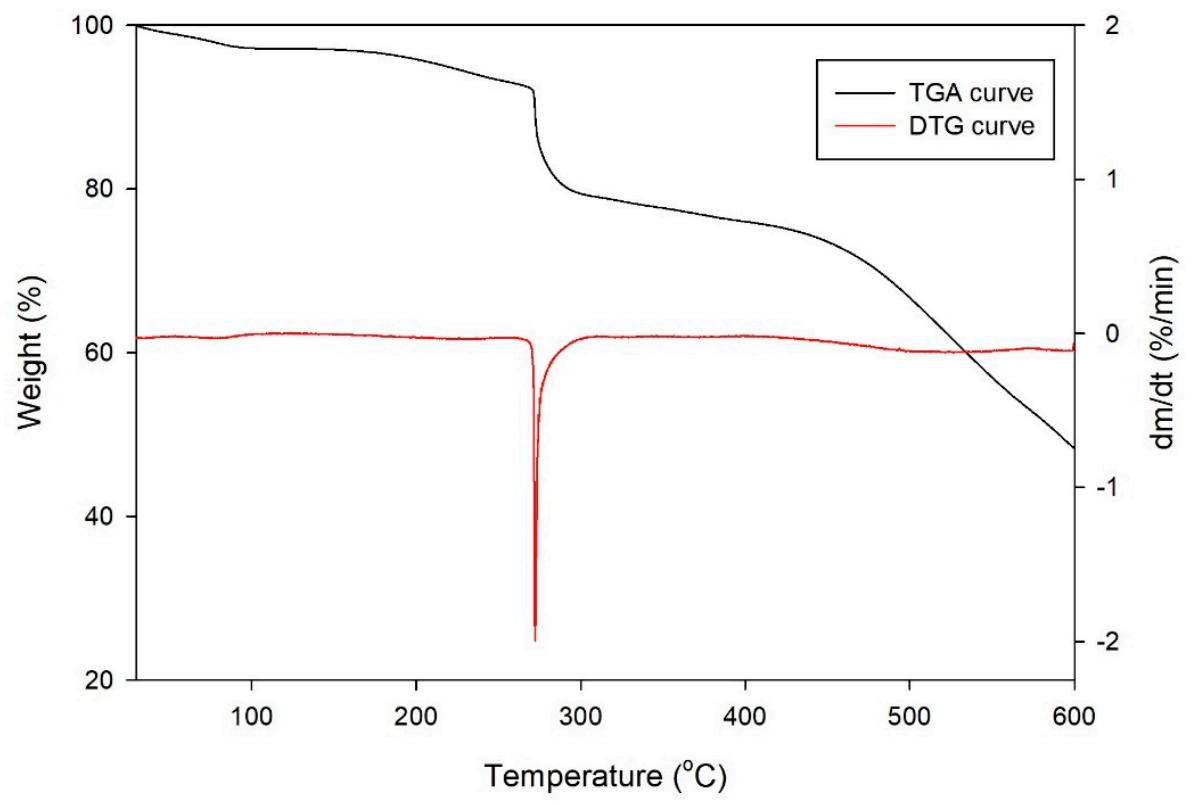

Figure 10. TGA and DTG curves of ZIF-L.

\section{Materials and Methods}

\subsection{Materials}

The zinc nitrate hexahydrate $\left(\mathrm{Zn}\left(\mathrm{NO}_{3}\right)_{2} \cdot 6 \mathrm{H}_{2} \mathrm{O}\right)$, 2-methylimidazole (Hmim) and crystal violet dye $(\mathrm{CV})$ were purchased from Sigma-Aldrich (Singapore). All of the chemicals were analytical grade, and were used without further treatment.

\subsection{Synthesis of ZIF-L}

The ZIF-L was synthesized from $\mathrm{Zn}\left(\mathrm{NO}_{3}\right)_{2} \cdot 6 \mathrm{H}_{2} \mathrm{O}$ as the metal source and Hmim as the ligand. A metal solution $(0.075 \mathrm{M})$ was prepared in $40 \mathrm{~mL}$ distilled water. Another solution was prepared separately containing a specific ligand concentration in another $40 \mathrm{~mL}$ distilled water, in which the molar ratio of ligand to metal was varied by $5,7.5$ and 10. Both solutions were sonicated for $10 \mathrm{~min}$, such that the compounds were be well ionized in the solvent. The metal solution was added dropwise with the ligand solution under stirring. The mixture was kept at various temperatures $\left(10,30\right.$, and $\left.50{ }^{\circ} \mathrm{C}\right)$ for various reaction times $(60,120$, and $180 \mathrm{~min})$. In the meantime, the cloudy solution was obtained and then centrifuged for $10 \mathrm{~min}$ to separate the ZIF-L precipitation. The precipitation was washed with distilled water and ethanol (twice each), respectively, and dried overnight at $80{ }^{\circ} \mathrm{C}$.

\subsection{Adsorption of Crystal Violet Dye}

Here, the amounts of adsorbed CV on the ZIF-L were used as the response in the statistical optimization of the ZIF-L preparation. A dye solution was prepared at a concentration of $1000 \mathrm{mg} / \mathrm{L}$. The adsorption was carried out by adding $10 \mathrm{mg}$ ZIF-L into $10 \mathrm{~mL}$ dye solution. It was shaken at room temperature for $24 \mathrm{~h}$ using a Memmert type WB-14 shaking water bath. After the adsorption, the solution was separated from the solid by centrifugation. A UV/Vis spectrophotometer was then used to measure the remaining $\mathrm{CV}$ concentration in the solution at a maximum wavelength of $590 \mathrm{~nm}$. The amount of adsorbed CV on the ZIF-L was calculated by the following equation [41]:

$$
q=\left[\left(C_{i}-C_{r}\right) \times V / m\right]
$$

where $C_{i}$ and $C_{r}$ are the initial and remaining $C V$ concentrations (in $\mathrm{mg} / \mathrm{L}$ ), while $V$ and $m$ are the volume of the CV solution and the mass of ZIF-L. The adsorption was performed for all of the ZIF-L obtained from the combined synthesis parameters. 


\subsection{Design of the Experiment}

\subsubsection{One-Factor-at-a-Time (OFAT) Method}

The ZIF-L was prepared using the independent parameters mentioned in Table 4 with an OFAT method. Then, the adsorption of the $\mathrm{CV}$ was conducted in order to measure the $q$ response for each ZIF-L. OFAT was used as the preliminary level determination before conducting the optimization analysis. Moreover, it was used as the early investigation of each parameter's effect on the synthesis of ZIF-L.

Table 4. Parameters and levers of the OFAT experiments.

\begin{tabular}{lcccc}
\hline Parameters & \multicolumn{3}{c}{ Levels } \\
\hline Molarratioofligandtometal $(r)$ & 2.5 & 5 & 7.5 & 10 \\
Reactiontime $(t$ in min $)$ & 30 & 60 & 120 & 180 \\
Temperature $\left(T\right.$, in $\left.^{\circ} \mathrm{C}\right)$ & 10 & 30 & 50 & 70 \\
\hline
\end{tabular}

\subsubsection{Response Surface Methodology}

The central composite design (CCD) of the response surface methodology (RSM) using Minitab 19 statistical software was applied to design the synthesis of ZIF-L involving cube, axial and center points. There were three independent parameters used, i.e., the molar ratio of ligand to metal $(r)$, reaction time $(t)$ and temperature $(T)$. Each parameter had three desired levels and two statistically additional levels, as described in Table 5. All of the combined parameters were repeated three times, such that there were 60 independent experiments in total. The RSM included the analysis of variance (ANOVA) in the determination of the significance of the parameters and their interactions.

Table 5. Uncoded and coded levels of the independent parameters.

\begin{tabular}{cccc}
\hline \multirow{2}{*}{ Coded Levels } & \multicolumn{3}{c}{ Parameters } \\
\cline { 2 - 4 } & $\begin{array}{c}\text { Molar ratio of Ligand to Metal } \\
(\boldsymbol{r})\end{array}$ & $\begin{array}{c}\text { Reaction Time } \\
(\boldsymbol{t} \text { in } \mathbf{~ m i n})\end{array}$ & $\begin{array}{c}\text { Temperature } \\
\left(\boldsymbol{T} \text { in }{ }^{\circ} \mathbf{C}\right)\end{array}$ \\
\hline-1.68 & 3.30 & 19 & -3.6 \\
-1 & 5 & 60 & 10 \\
0 & 7.5 & 120 & 30 \\
+1 & 10 & 180 & 50 \\
+1.68 & 11.70 & 221 & 63.6 \\
\hline
\end{tabular}

\subsubsection{Optimization}

RSM was employed in order to optimize the synthesis of ZIF-L statistically. Herein, the optimum condition was a synthesis condition that produced ZIF-L with the highest adsorption capacity towards crystal violet dye. The linear and quadratic effects of the independent parameters are mathematically expressed by the following equation [42,43]:

$$
Y=\alpha_{0}+\sum_{i=1}^{i} \alpha_{i} X_{i}+\sum_{i=1}^{i} \alpha_{i i} X_{i}^{2}+\sum_{i=1}^{i} \sum_{j=1}^{j} \alpha_{i j} X_{i} X_{j}
$$

where $Y$ is the predicted amount of dye adsorbed onto ZIF-L (in mg/L); $X_{i}$ and $X_{j}$ are the independent parameters used; and $\alpha_{0}, \alpha_{i}, \alpha_{i i}$, and $\alpha_{i j}$ are the intercept, linear, quadratic, and two-way interaction coefficients, respectively. Furthermore, this statistical analysis was carried out to represent the significance of the independent parameters ( $p$-value $<0.05$ ).

\subsection{Characterizations}

An X-ray diffraction (XRD) pattern was obtained by a PANalytical X'Pert Pro X-ray diffractometer with $\mathrm{Cu} \mathrm{K} \alpha_{1}$ radiation $(\lambda=1.5406 \AA)$. It was conducted at $40 \mathrm{kV}$ and $30 \mathrm{~mA}$ using a step size of $0.02^{\circ} /$ step. Scanning electron microscopy (SEM) was performed using 
a JSM-6390 field emission SEM, JEOL, Ltd., Japan, at an accelerating voltage of $10 \mathrm{kV}$ and a working distance of $7.5 \mathrm{~mm}$. The samples were prepared using a JFC-1200 coater, JEOL, Ltd., Japan, in an argon atmosphere. A Fourier transform infrared spectrophotometer (FTIR) was used to depict the spectra, indicating the samples' functional groups. This analysis was carried out using an FTIR Shimadzu $8400 \mathrm{~S}$ with the KBr pelleting method at a wavenumber range of $4000-400 \mathrm{~cm}^{-1}$. Thermalgravimetric analysis (TGA) was conducted using a Perkin Elmer Diamond TG/DTA thermal analyzer. It was carried out in a nitrogen gas flow of $150 \mathrm{~mL} / \mathrm{min}$ at a constant heating and cooling rate in a temperature range of $27.5-600{ }^{\circ} \mathrm{C}$.

\section{Conclusions}

The synthesis of ZIF-L was successfully carried out under the optimum conditions obtained from the optimization analysis. Statistically, the CCD in RSM was well fitted with the synthesis data, where the optimum condition was the synthesis process using a molar ratio of ligand to metal of 8.2220 for $97 \mathrm{~min}$ at $29^{\circ} \mathrm{C}$. This synthesis process is economically promising to produce high-quality ZIF-L, where the molar ratio used was lower than that in previous studies. The ZIF-L produced had a homogeneous starfruit-like shape with excellent crystallinity and thermal stability. It is a promising advanced material that can be used in various applications.

Author Contributions: Conceptualization, C.J.W., S.I., H.W.A. and S.G.; methodology, C.J.W. and S.G.; software, C.J.W.; validation, C.J.W., S.I. and S.G.; formal analysis, C.J.W. and H.W.A.; investigation, C.J.W. and S.I.; resources, S.I. and S.G.; data curation, C.J.W.; writing-original draft preparation, C.J.W.; writing-review and editing, C.J.W., S.I. and S.G.; visualization, C.J.W.; supervision, S.I. and S.G.; project administration, C.J.W., S.I., H.W.A. and S.G.; funding acquisition, S.I., H.W.A. and S.G. All authors have read and agreed to the published version of the manuscript.

Funding: This research was funded by the Directorate General of Resources for Science, Technology and Higher Education of the Republic of Indonesia, grant number 775/PKS/ITS/2021.

Institutional Review Board Statement: Not applicable.

Informed Consent Statement: Not applicable.

Data Availability Statement: Not applicable.

Conflicts of Interest: The authors declare no conflict of interest.

Sample Availability: Samples of the compounds are available from the authors.

\section{References}

1. He, Y.; Shi, L.; Wang, J.; Yan, J.; Chen, Y.; Wang, X.; Song, Y.; Han, G. UiO-66-NDC (1,4-naphthalenedicarboxilic acid) as a novel fluorescent probe for the selective detection of $\mathrm{Fe}^{3+}$. J. Solid State Chem. 2020, 285, 121206. [CrossRef]

2. Jian, M.; Liu, B.; Liu, R.; Qu, J.; Wang, H.; Zhang, X. Water-based synthesis of zeolitic imidazolate framework-8 with high morphology level at room temperature. RSC Adv. 2015, 5, 48433-48441. [CrossRef]

3. Sun, S.; Yang, Z.; Cao, J.; Wang, Y.; Xiong, W. Copper-doped ZIF-8 with high adsorption performance for removal of tetracycline from aqueous solution. J. Solid State Chem. 2020, 285, 121219. [CrossRef]

4. Zhao, H.; Li, Q.; Wang, Z.; Wu, T.; Zhang, M. Synthesis of MIL-101(Cr) and its water adsorption performance. Microporous Mesoporous Mater. 2020, 297, 110044. [CrossRef]

5. Zhuang, S.; Liu, Y.; Wang, J. Mechanistic insight into the adsorption of diclofenac by MIL-100: Experiments and theoretical calculations. Environ. Pollut. 2019, 253, 616-624. [CrossRef] [PubMed]

6. Ediati, R.; Dewi, S.K.; Hasan, M.R.; Kahardina, M.; Murwani, I.K.; Nadjib, M. Mesoporous HKUST-1 synthesized using solvothermal method. Rasayan J. Chem. 2019, 12, 1653-1659. [CrossRef]

7. Masoumi, S.; Tabrizi, F.F.; Sardarian, A.R. Efficient tetracycline hydrochloride removal by encapsulated phosphotungstic acid (PTA) in MIL-53 (Fe): Optimizing the content of PTA and recycling study. J. Environ. Chem. Eng. 2020, 8, 103601. [CrossRef]

8. Mao, Y.; Qi, H.; Ye, G.; Han, L.; Zhou, W.; Xu, W.; Sun, Y. Green and time-saving synthesis of MIL-100(Cr) and its catalytic performance. Microporous Mesoporous Mater. 2019, 274, 70-75. [CrossRef]

9. Mon, M.; Bruno, R.; Tiburcio, E.; Casteran, P.E.; Ferrando-Soria, J.; Armentano, D.; Pardo, E. Efficient Capture of Organic Dyes and Crystallographic Snapshots by a Highly Crystalline Amino-Acid-Derived Metal-Organic Framework. Chem. A Eur. J. 2018, 24, 17712-17718. [CrossRef] [PubMed] 
10. Alivand, M.S.; Tehrani, N.H.M.H.; Shafiei-Alavijeh, M.; Rashidi, A.; Kooti, M.; Pourreza, A.; Fakhraie, S. Synthesis of a modified HF-free MIL-101(Cr) nanoadsorbent with enhanced $\mathrm{H}_{2} \mathrm{~S} / \mathrm{CH}_{4}, \mathrm{CO}_{2} / \mathrm{CH}_{4}$, and $\mathrm{CO}_{2} / \mathrm{N}_{2}$ selectivity. J. Environ. Chem. Eng. 2019, 7, 102946. [CrossRef]

11. Cui, X.; Sun, X.; Liu, L.; Huang, Q.; Yang, H.; Chen, C. In-situ fabrication of cellulose foam HKUST-1 and surface modi fi cation with polysaccharides for enhanced selective adsorption of toluene and acidic dipeptides. Chem. Eng. J. 2019, 369, 898-907. [CrossRef]

12. Mon, M.; Bruno, R.; Ferrando-Soria, J.; Armentano, D.; Pardo, E. Metal-organic framework technologies for water remediation: Towards a sustainable ecosystem. J. Mater. Chem. A 2018, 6, 4912-4947. [CrossRef]

13. Chaturvedi, G.; Kaur, A.; Umar, A.; Khan, M.A.; Algarni, H.; Kansal, S.K. Removal of fluoroquinolone drug, levofloxacin, from aqueous phase over iron based MOFs, MIL-100(Fe). J. Solid State Chem. 2020, 281, 121029. [CrossRef]

14. He, Y.; Zeng, L.; Feng, Z.; Zhang, Q.; Zhao, X.; Ge, S.; Hu, X.; Lin, H. Preparation, characterization, and photocatalytic activity of novel AgBr/ZIF-8 composites for water purification. Adv. Powder Technol. 2020, 31, 439-447. [CrossRef]

15. Chu, F.; Zheng, Y.; Wen, B.; Zhou, L.; Yan, J.; Chen, Y. Adsorption of toluene with water on zeolitic imidazolate framework8/graphene oxide hybrid nanocomposites in a humid atmosphere. RSC Adv. 2018, 8, 2426-2432. [CrossRef]

16. Elhussein, E.A.A.; Şahin, S.; Bayazit, Ş.S. Removal of carbamazepine using UiO-66 and UiO-66/graphene nanoplatelet composite. J. Environ. Chem. Eng. 2020, 8, 2-9. [CrossRef]

17. Fan, C.; Dong, H.; Liang, Y.; Yang, J.; Tang, G.; Zhang, W.; Cao, Y. Sustainable synthesis of HKUST-1 and its composite by biocompatible ionic liquid for enhancing visible-light photocatalytic performance. J. Clean. Prod. 2019, 208, 353-362. [CrossRef]

18. Pangestu, T.; Kurniawan, Y.; Soetaredjo, F.E.; Santoso, S.P.; Irawaty, W.; Yuliana, M.; Hartono, S.B.; Ismadji, S. The synthesis of biodiesel using copper based metal-organic framework as a catalyst. J. Environ. Chem. Eng. 2019, 7, 103277. [CrossRef]

19. Kumar, A.; Chowdhuri, A.R.; Kumari, A.; Sahu, S.K. IRMOF-3: A fluorescent nanoscale metal organic frameworks for selective sensing of glucose and Fe (III) ions without any modification. Mater. Sci. Eng. C 2018, 92, 913-921. [CrossRef] [PubMed]

20. Shi, Z.; Yu, Y.; Fu, C.; Wang, L.; Li, X. Water-based synthesis of zeolitic imidazolate framework-8 for $\mathrm{CO}_{2}$ capture. RSC Adv. 2017, 7, 29227-29232. [CrossRef]

21. Tzitzios, V.; Kostoglou, N.; Giannouri, M.; Basina, G.; Tampaxis, C.; Charalambopoulou, G.; Steriotis, T.; Polychronopoulou, K.; Doumanidis, C.; Mitterer, C.; et al. Solvothermal synthesis, nanostructural characterization and gas cryo-adsorption studies in a metal-organic framework (IRMOF-1) material. Int. J. Hydrog. Energy 2017, 42, 23899-23907. [CrossRef]

22. Simon, M.A.; Anggraeni, E.; Soetaredjo, F.E.; Santoso, S.P.; Irawaty, W.; Thanh, T.C.; Hartono, S.B.; Yuliana, M.; Ismadji, S. Hydrothermal Synthesize of HF-Free MIL-100(Fe) for Isoniazid-Drug Delivery. Sci. Rep. 2019, 9, 1-11. [CrossRef]

23. Strzempek, W.; Menaszek, E.; Gil, B. Fe-MIL-100 as drug delivery system for asthma and chronic obstructive pulmonary disease treatment and diagnosis. Microporous Mesoporous Mater. 2019, 280, 264-270. [CrossRef]

24. Safaei, M.; Foroughi, M.M.; Ebrahimpoor, N.; Jahani, S.; Omidi, A.; Khatami, M. A review on metal-organic frameworks: Synthesis and applications. Trends Anal. Chem. 2019, 118, 401-425. [CrossRef]

25. Son, Y.R.; Ryu, S.G.; Kim, H.S. Rapid adsorption and removal of sulfur mustard with zeolitic imidazolate frameworks ZIF-8 and ZIF-67. Microporous Mesoporous Mater. 2020, 293, 109819. [CrossRef]

26. Abdelhamid, H.N.; Zou, X. Template-free and room temperature synthesis of hierarchical porous zeolitic imidazolate framework nanoparticles and their dye and $\mathrm{CO}_{2}$ sorption. Green Chem. 2018, 20, 1074-1084. [CrossRef]

27. Li, R.; Li, W.; Jin, C.; He, Q.; Wang, Y. Fabrication of ZIF-8@ $\mathrm{TiO}_{2}$ micron composite via hydrothermal method with enhanced absorption and photocatalytic activities in tetracycline degradation. J. Alloys Compd. 2020, 825, 154008. [CrossRef]

28. Lee, Y.; Jang, M.; Cho, H.; Kwon, H.; Kim, S.; Ahn, W. ZIF-8: A comparison of synthesis methods. Chem. Eng. J. 2015, 271, 276-280. [CrossRef]

29. Santoso, E.; Ediati, R.; Istiqomah, Z.; Sulistiono, D.O.; Nugraha, R.E.; Kusumawati, Y.; Bahruji, H.; Prasetyoko, D. Facile synthesis of ZIF-8 nanoparticles using polar acetic acid solvent for enhanced adsorption of methylene blue. Microporous Mesoporous Mater. 2021, 310, 110620. [CrossRef]

30. Huang, C.; Zhang, H.; Zheng, K.; Zhang, Z.; Jiang, Q.; Li, J. Two-dimensional hydrophilic ZIF-L as a highly-selective adsorbent for rapid phosphate removal from wastewater. Sci. Total Environ. 2021, 785, 147382. [CrossRef]

31. Zhang, F.; Dou, J.; Zhang, H. Mixed membranes comprising carboxymethyl cellulose (as capping agent and gas barrier matrix) and nanoporous ZIF-L nanosheets for gas separation applications. Polymers 2018, 10, 1340. [CrossRef]

32. Zhong, Z.; Yao, J.; Chen, R.; Low, Z.; He, M.; Liu, J.Z.; Wang, H. Oriented two-dimensional zeolitic imidazolate framework-L membranes and their gas permeation properties. J. Mater. Chem. A 2015, 3, 15715-15722. [CrossRef]

33. Chen, R.; Yao, J.; Gu, Q.; Smeets, S.; Baerlocher, C.; Gu, H.; Zhu, D.; Morris, W.; Yaghi, O.M.; Wang, H. A two-dimensional zeolitic imidazolate framework with a cushion-shaped cavity for $\mathrm{CO}_{2}$ adsorption. Chem. Commun. 2013, 49, 9500-9502. [CrossRef] [PubMed]

34. Khan, I.U.; Othman, M.H.D.; Ismail, A.F.; Ismail, N.; Jaafar, J.; Hashim, H.; Rahman, M.A.; Jilani, A. Structural transition from two-dimensional ZIF-L to three-dimensional ZIF-8 nanoparticles in aqueous room temperature synthesis with improved $\mathrm{CO}_{2}$ adsorption. Mater. Charact. 2018, 136, 407-416. [CrossRef]

35. Gross, A.F.; Sherman, E.; Vajo, J.J. Aqueous room temperature synthesis of cobalt and zinc sodalite zeolitic imidizolate frameworks. Dalt. Trans. 2012, 41, 5458-5460. [CrossRef] [PubMed] 
36. Kida, K.; Okita, M.; Fujita, K.; Tanaka, S.; Miyake, Y. Formation of high crystalline ZIF-8 in an aqueous solution. CrystEngComm 2013, 15, 1794-1801. [CrossRef]

37. Tran, B.L.; Chin, H.Y.; Chang, B.K.; Chiang, A.S.T. Dye adsorption in ZIF-8: The importance of external surface area. Microporous Mesoporous Mater. 2019, 277, 149-153. [CrossRef]

38. Ding, B.; Wang, X.; Xu, Y.; Feng, S.; Ding, Y.; Pan, Y.; Xu, W.; Wang, H. Hydrothermal preparation of hierarchical ZIF-L nanostructures for enhanced $\mathrm{CO}_{2}$ capture. J. Colloid Interface Sci. 2018, 519, 38-43. [CrossRef]

39. Valencia, L.; Abdelhamid, H.N. Nanocellulose leaf-like zeolitic imidazolate framework (ZIF-L) foams for selective capture of carbon dioxide. Carbohydr. Polym. 2019, 213, 338-345. [CrossRef]

40. Mahmoodi, N.M.; Keshavarzi, S.; Oveisi, M.; Rahimi, S.; Hayati, B. Metal-organic framework (ZIF-8)/inorganic nanofiber (Fe $\mathrm{O}_{3}$ ) nanocomposite: Green synthesis and photocatalytic degradation using LED irradiation. J. Mol. Liq. 2019, 291, 111333. [CrossRef]

41. Wijaya, C.J.; Ismadji, S.; Aparamarta, H.W.; Gunawan, S. Hydrophobic modification of cellulose nanocrystals from bamboo shoots using rarasaponins. ACS Omega 2020, 5, 20967-20975. [CrossRef] [PubMed]

42. Wijaya, C.J.; Ismadji, S.; Aparamarta, H.W.; Gunawan, S. Optimization of cellulose nanocrystals from bamboo shoots using Response Surface Methodology. Heliyon 2019, 5, e02807. [CrossRef] [PubMed]

43. Yuliana, M.; Sutrisno, R.J.; Hermanto, S.; Ismadji, S.; Wijaya, C.J.; Santoso, S.P.; Soetaredjo, F.E.; Ju, Y.-H. Hydrophobic Cetyltrimethylammonium Bromide-Pillared Bentonite as an Effective Palm Oil Bleaching Agent. ACS Omega 2020, 5, 28844-28855. [CrossRef] [PubMed] 